\title{
Randomized, Double-Blind, Placebo-Controlled Trial of Polyethylene Glycol (MiraLAX®) for Urinary Urge Symptoms
}

\author{
Nicol Corbin Bush, MD, \\ Departments of Pediatric Urology University of Texas Southwestern Medical Center, Dallas, \\ Texas
}

\begin{abstract}
Anjana Shah, CNP, Departments of Pediatric Urology University of Texas Southwestern Medical Center, Dallas, Texas
\end{abstract}

Theodore Barber, MD, Departments of Urologic Consultants, P.C., Grand Rapids, Michigan

Mary Yang, MD, Departments of Pediatric Radiology University of Texas Southwestern Medical Center, Dallas, Texas

Ira Bernstein, PhD, and

Departments of Clinical Science University of Texas Southwestern Medical Center, Dallas, Texas

Warren Snodgrass, MD

Departments of Pediatric Urology University of Texas Southwestern Medical Center, Dallas, Texas

\begin{abstract}
OBJECTIVE-Polyethylene glycol (PEG) is common first-line therapy for urinary symptoms despite minimal evidence-based support. We performed a randomized, double-blind, placebocontrolled study of PEG for initial treatment of urinary urge symptoms.
\end{abstract}

PATIENTS AND METHODS-Patients aged $>3$ years underwent baseline urinary symptom questionnaire (USQ, scored 0-16), bowel symptom questionnaire (scored 0-20) and abdominal xray (KUB). Patients were randomized to placebo/PEG regardless of parent's perception of constipation. After 1 month, patients completed follow-up questionnaires and KUB. Improvement was defined as decrease in USQ ( $\triangle$ USQ) $\geq 3$ points. Secondary analyses compared urinary and bowel symptoms to KUB.

RESULTS-Of 138 enrolled patients, 71 (51.4\%) completed 1 month of therapy. Analyses of those randomized to placebo versus PEG and non-completers demonstrated similar demographics, baseline symptoms, and KUB. Patients treated with placebo and PEG both had significant improvement in USQ scores $(\mathrm{p}<0.0001)$. Patients treated with PEG responded similar to placebo

(C) 2012 Journal of Pediatric Urology Company. Published by Elsevier Ltd. All rights reserved.

Address for reprints and correspondence: Nicol Bush, Department of Pediatric Urology, UT Southwestern Medical Center, 2350 Stemmons Frwy, Suite D-4300, MC F4.04, Dallas, TX 75207, nicol.bush@ childrens.com, 214-456-0619, fax 214-456-2497.

Publisher's Disclaimer: This is a PDF file of an unedited manuscript that has been accepted for publication. As a service to our customers we are providing this early version of the manuscript. The manuscript will undergo copyediting, typesetting, and review of the resulting proof before it is published in its final citable form. Please note that during the production process errors may be discovered which could affect the content, and all legal disclaimers that apply to the journal pertain.

Financial Disclosures: None

Conflicts of Interest: None 
( $\triangle$ USQ 3.7 vs. 3.4, p=0.773), with improvement in nearly half (48.5\% PEG vs. $44.7 \%$ placebo). There was no correlation between KUB and urinary or bowel symptoms.

CONCLUSIONS-Nearly $50 \%$ of patients with urinary urge symptoms treated with either placebo or PEG for 1 month had improvement in urinary symptoms. KUB did not correlate with baseline or follow-up urinary or bowel symptoms.

\section{INTRODUCTION}

Many children with urinary symptoms also experience bowel-related issues, generally called Bladder and Bowel Dysfunction (BBD). Overactive bladder (OAB), defined by the International Children's Continence Society as urinary urgency (a sudden and unexpected need to void), is commonly present in children with $\mathrm{BBD}$, often in conjunction with urinary frequency, holding maneuvers, and/or diurnal incontinence.[1] Urinary symptoms such as $\mathrm{OAB}$ and frequency have been linked to urinary tract infection (UTI), vesicoureteral reflux, and urinary incontinence [2-14].

Constipation has also been associated with UTI, reflux, and urinary incontinence in children, [15-16] and treatment for constipation has been reported to reduce incontinence and UTI in children with fecal incontinence [16]. Possibly influenced by this report, treatment for presumed constipation has become first-line therapy for many patients referred for BBD despite minimal evidence-based support in children without fecal incontinence [17-18]. We questioned whether treatment of constipation would improve $\mathrm{OAB}$ symptoms, and chose to use polyethylene glycol 3350 (PEG), an osmotic agent to stimulate stooling, because of its safety in children, popularity in clinical practice, and ease for creating a similar-appearing placebo. Prior randomized, placebo-controlled studies of constipated patients demonstrated improved stooling within 2 weeks with PEG therapy [19]. Thus, we performed a 4-week, double-blind, randomized trial to determine if PEG is effective as a first-line therapy in children with urinary urge symptoms. Our primary outcome variable was improvement in OAB symptoms as measured by urinary symptom questionnaire (USQ), with the underlying hypothesis that PEG would improve urinary urge symptoms compared to placebo.

We also questioned whether symptoms of either bladder or bowel function by questionnaire correlated with constipation diagnosed by fecal load on KUB, given that radiologic assessment is performed by some subspecialists to detect constipation. Therefore, a secondary aim of our study was to determine if KUB fecal load correlated with OAB or bowel symptoms at study entry or after 1 month of therapy.

\section{METHODS}

\section{Design}

A prospective randomized, double-blind, placebo controlled study was performed to determine if PEG was effective for decreasing OAB symptoms.

\section{Study population}

Patients referred to a multi-provider pediatric urology clinic from February 2008-March 2011 were screened for study participation on their initial visit if they were diagnosed with primarily $\mathrm{OAB}$ (urge) symptoms, whereas those referred for urinary tract infections, primary nocturnal enuresis, and/or urge symptoms less than 6 months were not offered study participation. The clinician queried eligible parents and patients using a modified Vancouver urinary symptom questionnaire (USQ, Table 1a) with a rating scale to assess 4 urge-related symptoms [20]. Scores ranged from 0 (no urge symptoms) to 16 (all 4 symptoms occurring almost always). Study inclusion criteria were age 3-18 years with USQ scores more than 4. 
Patients with prior PEG treatment, anorectal and/or neurologic disorders, and urinary symptoms less than 6 months were excluded. The study protocol was approved by the University of Texas Southwestern Institutional Review Board. Informed consent was obtained from the parent/caregiver and assent was given by children aged 10 and older.

\section{Measures}

In addition to the USQ, a similar rating-scale bowel symptom questionnaire (BSQ, Table $1 \mathrm{~b}$ ) (scored from 0-20) and kidney-ureter-bladder abdominal radiograph (KUB) for fecal load were performed on the first clinic visit. Parents filled out the questionnaires with answers provided by the patients and confirmed by the provider. KUB grading was performed by a pediatric radiologist (MY) blinded to treatment group. Two commonly used validated fecal load grading scales were used, as originally described by Leech and Blethyn [21-22]. Radiographic evidence of constipation was separately defined as a Leech score $\geq 8$ or a Blethyn score $\geq 2$ per the constipation criteria associated with these scales (Appendix) [21-22]. There were no other therapies discussed or prescribed to enrolled patients during the study, such as timed voiding, anticholinergics, or hydration/dietary changes.

\section{Randomization and Intervention}

Patients were randomized by the Children's Medical Center investigational drug pharmacist, blinded to patient data except age, according to a computer-generated list stratified into 2 age groups: 3-6 years and 7-18 years. Patient and provider were blinded during allocation, treatment, and post-treatment assessment. The pharmacist distributed 8.5 grams PEG (3-6 years) or 17.0 grams (7-18 years) versus placebo, a comparable weight of 7\% dextrose in the same volume, regardless of parent's or patient's perception of constipation and KUB results. A reminder telephone call was made after 2 weeks to assess medical compliance and/or side effects and confirm their 1 month follow up appointment. At a second clinic visit after 1 month of treatment, patients completed follow-up USQ and BSQ questionnaires, were queried about medication compliance, and underwent KUB. Patients taking $<3$ weeks of the assigned medication were excluded from the per-protocol analysis.

\section{Statistical Analysis}

The primary outcome was change in USQ score ( $\triangle$ USQ) from baseline among patients completing 1 month of therapy, with higher $\triangle$ USQ demonstrating greater symptom improvement (i.e. less urinary urge symptoms). The Wilcoxon signed rank test was used to analyze within-group changes in the pre- and post-treatment USQ scores, and the MannWhitney $\mathrm{U}$ test analyzed between-group difference in $\triangle \mathrm{USQ}$ among those assigned placebo compared to PEG. Results were calculated for patients returning after 1 month of therapy (per-protocol analysis), and for all patients (intention to treat analysis), with the initial USQ score used for the follow up score in those who did not return at 1 month. Improvement was defined as $\triangle \mathrm{USQ} \geq 3$ points, chosen because of perceived clinical significance of approximately $20 \%$ symptom improvement, such as a change from rushing to the bathroom almost always to less than $1 / 2$ of the time. Complete symptom improvement was defined as follow-up total USQ score $\leq 4$. The Wilcoxon signed rank test and the Mann-Whitney U test were also used to analyze within-group and between-group differences in the change of preand post-treatment BSQ scores. Secondary analyses compared baseline and follow-up USQ and BSQ scores to patients' baseline and follow-up KUB fecal load scores using Spearman's correlation.

Sample size was calculated with $80 \%$ power and $a=0.05$ [23]. Assuming a baseline USQ score of $14(\mathrm{SD}=4)$ and $25 \%$ improvement with PEG versus a 10\% response to placebo, 57 patients were required in each group using a 2-tailed Chi-square test, for a total of 114 patients. Allowing for $20 \%$ dropout, our goal was to enroll 136 patients. Statistical analyses 
were performed using Mann-Whitney U, Kruskal-Wallis, chi-square, Spearman's correlation, and Cronbach Coefficient Alpha. Analyses were performed with GraphPad Software version 5.04 (La Jolla, CA) and SAS Software Version 9.2 (SAS Institute, Inc., Cary, NC) after study completion. The level of significance was set at $a=0.05$ (two-tailed). Patients, providers, and radiologist remained blinded to treatment group, with unblinding by the investigational pharmacist shared with those performing data analysis at the completion of the study.

\section{RESULTS}

Of 138 enrolled patients, 85 (61.6\%) were female, with an average age of 7.3 years [standard deviation (SD) 2.3]. Of these, 71 (51.4\%) completed follow-up questionnaires after 1 month. Analyses of those randomized to placebo versus PEG and non-completers demonstrated similar baseline demographics, USQ scores, and BSQ scores (Table 2). Average dose of PEG was $0.45 \mathrm{grams} / \mathrm{kg} / \mathrm{day}$.

\section{Primary outcome}

As demonstrated in Table 2, patients completing 1 month of therapy with placebo and PEG both had significant improvement in OAB symptoms $(13.9 \rightarrow 10.5, \mathrm{p}<0.0001 ; 13.9 \rightarrow 10.2$, $\mathrm{p}<0.0001$ ) and bowel symptoms (BSQ 6.9 $\rightarrow 4.3, \mathrm{p}<0.0009 ; 5.9 \rightarrow 3.6, \mathrm{p}<0.0001$ ). However, patients treated with PEG and placebo responded similarly, with no difference in $\triangle$ USQ or $\triangle \mathrm{BSQ}$ scores between groups ( $\mathrm{p}=0.773$ and 0.914$)$, and similar percentages of patients with improvement ( $\triangle$ USQ $\geq 3$ points) in urinary symptoms [17 (44.7\%) placebo vs. $16(48.5 \%)$ PEG]. Five $(13 \%)$ patients assigned placebo versus $6(18 \%)$ assigned PEG had complete urine symptom improvement. Intention to treat analysis including all patients also showed significant improvement in USQ scores within both groups (placebo 14.0 $\rightarrow 12.1, \mathrm{p}=0.004$; PEG 13.6 $\rightarrow 11.8, p=0.007)$, with no difference in $\triangle \mathrm{USQ}$ between groups $(\mathrm{p}=0.839)$.

\section{Subset analyses}

Among 26 (36.6\%) patients with initial USQ scores of 16 (all 4 urge symptoms, almost always), USQ scores remained completely unchanged in 8 ( 4 on placebo, 4 on PEG), minimally changed in 7, and improved in 11 (7 on placebo, 4 on PEG), with no difference among those assigned PEG vs. placebo ( $\triangle$ USQ 3.36 vs. $4.40, \mathrm{p}=0.284$ ). Two patients, one each assigned to placebo and PEG, had complete symptom improvement. Subset analysis demonstrated there was no difference in baseline urinary scores between the patient age group categories 3-6 years compared to versus $\geq 7$ years (USQ 14.00 vs. $14.05, \mathrm{p}=0.477$ ), with similar improvement in post-treatment scores between groups ( $\mathrm{p}<0.0001$ for both). Likewise, pre- and post-scores were improved for both males and females (data not shown). We also analyzed data excluding question 4, eliminating the effects of enuresis/nocturia on symptom response. Patients assigned to PEG and placebo had similar improvement in USQ scores (PEG 10.79 $\rightarrow 7.97$, p $<0.0002$; placebo $10.74 \rightarrow 7.57$, $\mathrm{p}<0.0001$ ).

\section{Secondary outcomes}

Table 3 demonstrates baseline KUB fecal load scores before and after 1 month of therapy with PEG or placebo. The overall number of patients meeting KUB criteria for constipation remained virtually unchanged despite 1 month of placebo or PEG using both Blethyn and Leech criteria, with no difference in mean fecal loading scores before or after therapy. There was good correlation between Leech and Blethyn scoring (Spearman's $\mathrm{R}=0.78, \mathrm{p}<0.0001$ ), thus, reported results are limited to Leech scores. Spearman's correlation between baseline Leech fecal loading score and baseline USQ was not significant when analyzed for 130 enrolled patients with KUB data $(\mathrm{R}=-0.155, \mathrm{p}=0.079)$ (Fig 1), or for the subset of 71 patients completing 1 month of study drug $(\mathrm{R}=-0.144, \mathrm{p}=0.235)$. Similarly, there was no 
correlation in baseline fecal loading score with baseline BSQ scores ( $\mathrm{r}=-0.149, \mathrm{p}=0.278)$, or follow-up fecal load score with follow-up USQ or BSQ scores (data not shown). However, follow-up BSQ scores correlated with follow-up USQ $(r=0.48, p<0.001)$, such that patients with worse bowel symptoms on follow up were more likely to have worse urinary symptoms irrespective of treatment group and/or follow up KUB results. To analyze if rectal fecal load was associated with urinary or bowel symptoms, we analyzed the fecal load score for the 3rd bowel segment (distal colon and rectum) on the Leech scale, and again found no correlation with USQ ( $\mathrm{r}=-0.050, \mathrm{p}=0.600)$ or BSQ $(\mathrm{r}=-0.164, \mathrm{p}=0.218)$ scores.

We performed an exploratory subset analysis evaluating $\triangle \mathrm{USQ}$ for patients with and without constipation on KUB (Fig 2). While both groups improved, patients without KUBdefined constipation at baseline demonstrated more improvement in their urinary urge symptom scores on follow up than those with constipation $(\mathrm{p}=0.031)$. The differences were not significant for those receiving placebo compared to PEG $(\mathrm{p}=0.204)$.

\section{Study non-completers}

Of the 67 patients who did not complete the study, 40 were lost to follow-up. Of these, 6 families were reached by telephone, with 5 reporting improvement in urinary symptoms. 6 children were non-compliant and stopped medication early, 4 reporting no side effects, while 2 quit due to mild diarrhea ( 1 assigned to PEG, 1 to placebo). An additional child withdrew prior to starting medication because the parents decided not to participate after enrollment. Protocol violations occurred in 14 patients (KUB not performed prior to randomization, or error in USQ, BSQ, consent, or medication dispensing), and 6 patients had insurance lapses that precluded follow-up appointment.

\section{DISCUSSION}

In this randomized, double-blind study, both placebo and PEG were effective in improving symptoms of $\mathrm{OAB}$ as assessed before and after 1 month of therapy with a 4-symptom rating questionnaire of urinary urge symptoms (USQ). Urinary symptom improvement and complete response occurred in $17(44.7 \%)$ and $5(13 \%)$ patients assigned placebo compared to $16(48.5 \%)$ and $6(18 \%)$ assigned PEG. The OAB response rate in children in our study was similar to the $\mathrm{OAB}$ placebo response rate found in Cochrane meta-analysis, which reported $41 \%$ of adults assigned placebo report cure or improvement in OAB symptoms.[24]

We chose a 3-point (20\%) response on our 16-point scale since this was felt to represent clinically-significant improvement, such as a decrease in 1 of the urge symptoms from nearly all the time to less than half, or an incremental change in 3 of the 4 urge-related symptoms. The urinary improvement was sustained in 19/24 (79.2\%) patients who presented for 3 month follow-up, whereas 3 patients assigned to placebo and 2 to PEG had continued urge symptoms with minimal improvement or symptom worsening.

The reported association between $\mathrm{OAB}$ and constipation is important since anticholinergic drugs commonly prescribed for uninhibited bladder contractions and underlying urge symptoms can exacerbate stool retention and thereby prolong bladder dysfunction. However, it was our clinical impression that parents were not very familiar with bowel activity of their children after the usual age of toilet training, making history potentially unreliable for diagnosing constipation. Therefore, we initially recommended laxatives for 1 month in all patients presenting with primarily urge symptoms, reserving anticholinergic therapy for those whose bladder symptoms persisted. In a retrospective review of 110 children, $34 \%$ had relief of bladder symptoms with laxatives alone, with pre-treatment history of bowel function not predicting response.[25] However, that study lacked placebo 
control, prompting the current study. Our findings now demonstrate that symptom improvement occurs similarly in patients assigned to PEG or placebo.

\section{Placebo response}

We did not suggest timed voiding, recommend fluid/dietary changes, or prescribe anticholinergic therapy for patients enrolled in the study. Nonetheless, $44.7 \%$ of returning patients assigned to placebo had urinary symptom improvement, including 5 patients with complete symptom resolution. Given this larger-than-expected placebo response, we investigated whether the placebo could have caused an osmotic laxative response similar to PEG. The placebo consisted of $7 \%$ dextrose powder, which provided $70 \mathrm{mg} \mathrm{sugar} / \mathrm{mL}$. In comparison, a typical cola beverage provides $108 \mathrm{mg}$ sugar $/ \mathrm{mL}$. To our knowledge, dextrose-induced osmotic diarrhea has not been reported. While simple spontaneous resolution of urge symptoms is possible, we considered this less likely since patients were required to have at least 6 months of urge symptoms at study entry as confirmed by the pediatric urology provider.

Placebo response often varies by disease process but has been shown to have pervasive perceived (or actual) effects, including among patients told they were taking placebo compared to no-treatment controls.[25-26] Our results were similar to the Cochrane review findings that $41 \%$ of adults with $\mathrm{OAB}$ report symptom improvement or resolution on placebo.[24] Future studies of therapy for pediatric urinary urge symptoms should take into account the high placebo-response rate, which may indicate an as-yet unidentified mechanism for faster symptom reduction in this self-limited condition, or simply relate to enhanced patient and parental awareness of bowel and bladder habits. Alternatively, a study design incorporating a no-treatment control group could be considered.

\section{Urinary and bowel symptoms}

There was no correlation between baseline bowel symptoms and urinary urge symptoms. Despite widespread belief to the contrary, lack of direct correlation between urinary symptoms and constipation has been demonstrated previously.[27-29] While KUB-defined constipation did not change after 1 month of therapy with either placebo or PEG, mean BSQ scores improved along with the urinary symptoms. Although initial BSQ-rated bowel symptoms did not correlate with urinary symptoms, follow-up BSQ strongly correlated with the follow-up USQ $(r=0.48, p<0.001)$, possibly due to greater awareness of actual bowel activity by parents or patients at follow up. Providers should be aware that the link between urinary and bowel symptoms may not be present on the initial assessment, whereas the relationship is more apparent at follow up. Nonetheless, while children with more bowel symptoms as assessed by the BSQ at follow up had persistently worse urinary symptoms, KUB fecal load scores at follow up did not correlate with follow-up urinary or bowel symptoms, suggesting that bowel symptoms at follow up, and not KUB, should be used to guide further therapy.

\section{KUB fecal load}

We chose KUB to evaluate fecal load instead of rectal diameter on pelvic ultrasonography since inter- and intra-rater reliability, validity, and objectivity have not yet been defined for pelvic ultrasound as a diagnostic tool for constipation.[30] Using 2 different validated fecal load scales [17-18], half of the enrolled children demonstrated constipation despite minimal bowel symptoms as assessed by our baseline bowel questionnaire (BSQ). On one hand, this supports our impression that parents and patients may not be aware of bowel habits and underlying constipation. Conversely, one review article demonstrated conflicting evidence for radiographic diagnosis of constipation using the available published validated fecal load scores on KUB, including the Leech and Blethyn scales we used.[29] The synthesis of 
evidence showed KUB-defined constipation was equally present in clinically constipated and non-constipated children, and thus KUB may not be a reliable indicator of clinical constipation. Furthermore, in our patients there was no correlation between baseline or 1month follow-up urinary or bowel symptoms with KUB fecal load, such that some patients with high fecal load scores had less urinary symptoms, and vice-versa. Consequently, our data suggest that KUB for fecal load has no role in the diagnosis or management of urgerelated bladder symptoms.

\section{PEG dose}

Besides KUB fecal load being a poor predictor of clinical constipation (or lack of constipation), other possible causes of lack of KUB-improvement despite therapy with PEG include insufficient dose or duration. The manufacturer's recommended dose for adults (17 grams mixed in 8 ounces of liquid/day) was given for patients older than 6 years, a dose that has been shown to increase number of weekly bowel movements among constipated patients within 2 weeks.[19] Our younger patients aged 3-6 years had similar dosing per kilogram weight as those aged 7 and older ( 0.42 vs. 0.47 grams $/ \mathrm{kg} / \mathrm{day}, \mathrm{p}=0.219)$. A randomized, double-blind study comparing PEG with lactulose demonstrated an average PEG dose of $0.26(+/-0.11)$ grams $/ \mathrm{kg} / \mathrm{day}$ was well-tolerated for maintenance therapy of constipation, which we surpassed in this study.[31] However, an open-label study showed a dose of 0.8 $\mathrm{gm} / \mathrm{kg} /$ day (range 0.2-1.4) was the most effective therapy of fecal disimpaction, and some children are recommended therapy with as much as 1.0-1.5 grams $/ \mathrm{kg} /$ day for urinary symptoms.[32-33] Since our patients presented with urinary and not bowel-related complaints, medical disimpaction was not done. While lack of change in KUB fecal load might imply inadequate PEG dosing, we are not aware of any other longitudinal study reporting KUB findings during PEG therapy despite its common use.

Our findings have influenced our practice in several ways. Among patients with OAB, we continue to use PEG ( 0.45 grams $/ \mathrm{kg} / \mathrm{day})$ and explain to parents that $40-50 \%$ of children improve with this regimen. We are also quicker to move to anticholinergic therapy. Although there are limited randomized controlled trials of anticholinergic therapy for OAB in children, Cochrane meta-analysis of nearly 12,000 adults with OAB showed an additional $15 \%$ benefit (over the $41 \%$ placebo-response) in patients assigned to anticholinergic therapy. [34-35] [24] We no longer use KUB to assess constipation in children with OAB.

\section{Limitations}

To our knowledge, no other prospective, double-blind, placebo-controlled studies have addressed whether or not PEG or other constipation therapeutic regimens improve OAB symptoms in children. We show that PEG does indeed improve OAB symptoms, as does placebo. However, our study has several limitations, including a high drop-out rate and short follow-up. This was an institutional-sponsored study, and we were unable to provide transportation or incentive payments to patients, which may partially account for the high drop-out rate. The few non-completers we were able to contact reported urinary symptom improvement, which might explain why some did not return for follow up. Although patients not completing the study were equally assigned to placebo and PEG, it is possible some children experienced side effects such as diarrhea and chose not to continue participation. Nonetheless, intention-to-treat analysis confirmed that patients assigned to placebo and PEG had similar improvement in their urinary urge symptoms, with more than $40 \%$ of patients completing therapy demonstrating improvement in OAB symptoms.

We found recruitment difficult for several reasons. For example, some parents doubted any connection between bowel and bladder dysfunction and so declined bowel therapy for bladder symptoms. Additionally, widespread belief in our community that occult 
constipation can promote bladder dysfunction resulted in many patients being excluded due to recent or ongoing PEG treatment. Finally, we used a non-validated questionnaire for assessment. No pediatric voiding questionnaires have been validated longitudinally. Accordingly, we choose to use a rating system of urinary and bowel questions adapted from the validated Vancouver questionnaire to assess our patients [16], excluding questions which did not relate to urge voiding symptoms. The simple graded-scale response we used is commonly employed for before/after paired-measurement studies. In order to assess whether or not the responses were reasonable on our questionnaire, we performed Cronbach's alpha statistic, a measure of the internal consistency of psychometric tests, which supported the reliability of our abbreviated scale (alpha $=0.52, \mathrm{p}<0.001$ ). Furthermore, USQ scores subjectively appeared to match the urinary symptoms at initial and follow-up exams based upon clinical assessment.

\section{CONCLUSIONS}

Placebo and PEG work equally well for the initial treatment for urinary urge symptoms. Patients with urinary urge symptoms treated with either placebo or manufacturerrecommended PEG doses for 1 month had significant improvement in their urinary and bowel symptoms. Complete symptom resolution occurred in $13-18 \%$, and $45-48 \%$ had improvement of USQ scores without timed voiding, dietary changes, or anticholinergic therapy. There was no correlation between urinary urge symptoms or bowel symptoms and KUB-defined constipation using fecal load scores at baseline or on follow up, suggesting KUB has a limited role in children with OAB.

\section{Acknowledgments}

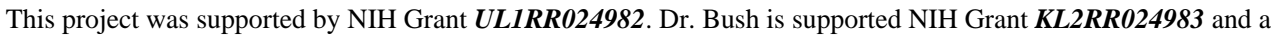
research grant from Coloplast. Thanks to Anjana Shah, Janelle Traylor and Karen Pritzker for patient recruitment, Tisha Franklin for manuscript assistance, and Ruth Merryman for pharmacy assistance.

\section{References}

[1]. Neveus T, von Gontard A, Hoebeke P, Hjalmas K, Bauer S, Bower W, Jorgensen TM, Rittig S, Walle JV, Yeung CK, Djurhuus JC. The standardization of terminology of lower urinary tract function in children and adolescents: report from the Standardisation Committee of the International Children's Continence Society. J Urol. Jul; 2006 176(1):314-324. [PubMed: 16753432]

[2]. Koff SA, Lapides J, Piazza DH. Association of urinary tract infection and reflux with uninhibited bladder contractions and voluntary sphincteric obstruction. J Urol. Sep; 1979 122(3):373-376. [PubMed: 470012]

[3]. Taylor CM, Corkery JJ, White RH. Micturition symptoms and unstable bladder activity in girls with primary vesicoureteric reflux. Br J Urol. Oct; 1982 54(5):494-498. [PubMed: 7171955]

[4]. McGuire EJ, Savastano JA. Urodynamic studies in enuresis and the nonneurogenic neurogenic bladder. J Urol. Aug; 1984 132(2):299-302. [PubMed: 6737581]

[5]. Passerini-Glazel G, Cisternino A, Camuffo MC, Ferrarese P, Aragona F, Artibani W. Videourodynamic studies of minor voiding dysfunctions in children: an overview of 13 years' experience. Scand J Urol Nephrol Suppl. 1992; 141:70-84. discussion 85-76. [PubMed: 1609255]

[6]. Lapides J, Diokno AC. Persistence of the infant bladder as a cause for urinary infection in girls. J Urol. Feb; 1970 103(2):243-248. [PubMed: 5410598]

[7]. Snodgrass W. Relationship of voiding dysfunction to urinary tract infection and vesicoureteral reflux in children. Urology. Oct; 1991 38(4):341-344. [PubMed: 1755143] 
[8]. Koff SA, Murtagh DS. The uninhibited bladder in children: effect of treatment on recurrence of urinary infection and on vesicoureteral reflux resolution. J Urol. Dec; 1983 130(6):1138-1141. [PubMed: 6606053]

[9]. Koff SA. Relationship between dysfunctional voiding and reflux. J Urol. Nov; 1992 148(5 Pt 2): 1703-1705. [PubMed: 1433592]

[10]. Koff SA, Wagner TT, Jayanthi VR. The relationship among dysfunctional elimination syndromes, primary vesicoureteral reflux and urinary tract infections in children. J Urol. Sep; 1998 160(3 Pt 2):1019-1022. [PubMed: 9719268]

[11]. Snodgrass W. The impact of treated dysfunctional voiding on the nonsurgical management of vesicoureteral reflux. J Urol. Nov; 1998 160(5):1823-1825. [PubMed: 9783967]

[12]. Chen JJ, Mao W, Homayoon K, Steinhardt GF. A multivariate analysis of dysfunctional elimination syndrome, and its relationships with gender, urinary tract infection and vesicoureteral reflux in children. J Urol. May; 2004 171(5):1907-1910. [PubMed: 15076307]

[13]. Klijn AJ, Uiterwaal CS, Vijverberg MA, Winkler PL, Dik P, de Jong TP. Home uroflowmetry biofeedback in behavioral training for dysfunctional voiding in school-age children: a randomized controlled study. J Urol. Jun; 2006 175(6):2263-2268. discussion 2268. [PubMed: 16697850]

[14]. Hoebeke P, Van Laecke E, Van Camp C, Raes A, Van De Walle J. One thousand videourodynamic studies in children with non-neurogenic bladder sphincter dysfunction. BJU Int. Apr; 2001 87(6):575-580. [PubMed: 11298061]

[15]. Yazbeck S, Schick E, O'Regan S. Relevance of constipation to enuresis, urinary tract infection and reflux. A review. Eur Urol. May.1987 13:318-321.

[16]. Loening-Baucke V. Urinary incontinence and urinary tract infection and their resolution with treatment of chronic constipation of childhood. Pediatrics. Aug; 1997 100(2 Pt 1):228-232. [PubMed: 9240804]

[17]. Cooper C, Crendron M. Voiding dysfunction and treament \& management. 2011 City.

[18]. Erickson BA, Austin JC, Cooper CS, Boyt MA. Polyethylene glycol 3350 for constipation in children with dysfunctional elimination. J Urol. Oct; 2003 170(4 Pt 2):1518-1520. [PubMed: 14501649]

[19]. DiPalma JA, DeRidder PH, Orlando RC, Kolts BE, Cleveland MB. A randomized, placebocontrolled, multicenter study of the safety and efficacy of a new polyethylene glycol laxative. Am J Gastroenterol. Feb; 2000 95(2):446-450. [PubMed: 10685748]

[20]. Afshar K, Mirbagheri A, Scott H, MacNeily AE. Development of a symptom score for dysfunctional elimination syndrome. J Urol. Oct; 2009 182(4 Suppl):1939-1943. [PubMed: 19695637]

[21]. Leech SC, McHugh K, Sullivan PB. Evaluation of a method of assessing faecal loading on plain abdominal radiographs in children. Pediatr Radiol. Apr; 1999 29(4):255-258. [PubMed: 10199902]

[22]. Blethyn AJ, Verrier Jones K, Newcombe R, Roberts GM, Jenkins HR. Radiological assessment of constipation. Arch Dis Child. Dec; 1995 73(6):532-533. [PubMed: 8546512]

[23]. Uitenbroek D. SISA Binomial. 1997 City.

[24]. Nabi G, Cody J, Ellis G, Hay-Smith J, Herbison G. Anticholinergic drugs versus placebo for overactive bladder syndrome in adults. The Cochrane Collaboration. 2009:1-84.

[25]. Baseman A, Snodgrass W. Empiric laxative therapy in children with urge syndrome. 2002 City.

[26]. Hrobjartsson A, Norup M. The use of placebo interventions in medical practice--a national questionnaire survey of Danish clinicians. Eval Health Prof. Jun; 2003 26(2):153-165. [PubMed: 12789709]

[27]. Bael AM, Benninga MA, Lax H, Bachmann H, Janhsen E, De Jong TP, Vijverberg M, Van Gool JD. Functional urinary and fecal incontinence in neurologically normal children: symptoms of one 'functional elimination disorder'? BJU Int. Feb; 2007 99(2):407-412. [PubMed: 17034497]

[28]. Allen HA, Austin JC, Boyt MA, Hawtrey CE, Cooper CS. Evaluation of constipation by abdominal radiographs correlated with treatment outcome in children with dysfunctional elimination. Urology. May; 2007 69(5):966-969. [PubMed: 17482944] 
[29]. Bijos A, Czerwionka-Szaflarska M, Mazur A, Romanczuk W. The usefulness of ultrasound examination of the bowel as a method of assessment of functional chronic constipation in children. Pediatr Radiol. Dec; 2007 37(12):1247-1252. [PubMed: 17952426]

[30]. Reuchlin-Vroklage LM, Bierma-Zeinstra S, Benninga MA, Berger MY. Diagnostic value of abdominal radiography in constipated children: a systematic review. Arch Pediatr Adolesc Med. Jul; 2005 159(7):671-678. [PubMed: 15997002]

[31]. Voskuijl W, de Lorijn F, Verwijs W, Hogeman P, Heijmans J, Makel W, Taminiau J, Benninga M. PEG 3350 (Transipeg) versus lactulose in the treatment of childhood functional constipation: a double blind, randomised, controlled, multicentre trial. Gut. Nov; 2004 53(11):1590-1594. [PubMed: 15479678]

[32]. Youssef NN, Peters JM, Henderson W, Shultz-Peters S, Lockhart DK, Di Lorenzo C. Dose response of PEG 3350 for the treatment of childhood fecal impaction. J Pediatr. Sep; 2002 141(3):410-414. [PubMed: 12219064]

[33]. Pashankar DS, Bishop WP. Efficacy and optimal dose of daily polyethylene glycol 3350 for treatment of constipation and encopresis in children. J Pediatr. Sep; 2001 139(3):428-432. [PubMed: 11562624]

[34]. Misselwitz J, John U, Tamminen-Mobius T, Lax-Gross H, Hirche H, van Gool I. OxybutynineHCI versus placebo in children with urodynamically proven urge syndrome-A placebo controlled study. 1999 City.

[35]. Ayan S, Kaya K, Topsakal K, Kilicarslan H, Gokce G, Gultekin Y. Efficacy of tolterodine as a first-line treatment for non-neurogenic voiding dysfunction in children. BJU Int. Aug; 2005 96(3):411-414. [PubMed: 16042740] 


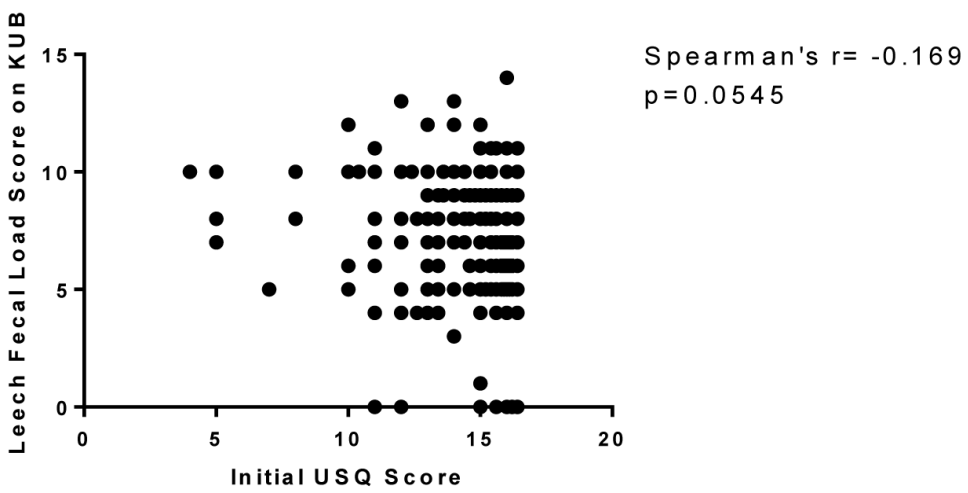

FIGURE 1.

Spearman's correlation of baseline Leech fecal loading scores (range 0-15) compared to baseline urinary urge symptom questionnaire responses (USQ, range 0-16), in 130 patients. 


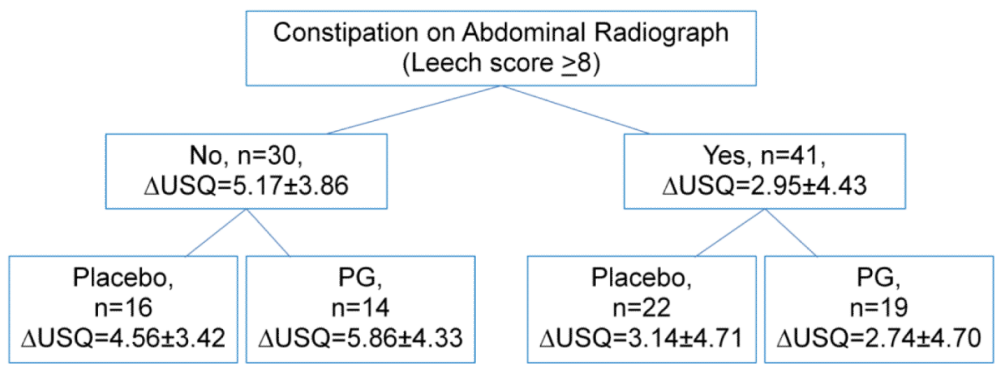

FIGURE 2.

Mean change in urinary urge symptom questionnaire scores ( $\triangle \mathrm{USQ} \pm$ Standard Deviation) for patients without radiographic evidence of constipation on baseline abdominal radiograph (Leech score <8) compared to those with constipation (Leech scores 28 ). Higher $\triangle$ USQ reflects more improvement in urinary urge symptom scores on follow up. Patients without constipation at baseline demonstrated more improvement than those with constipation $(\mathrm{p}=0.031)$. The differences were not significant for those receiving placebo compared to PEG $(\mathrm{p}=0.204)$. 
TABLE 1

Initial urinary symptom questionnaire (USQ) and bowel symptom questionnaire (BSQ). Follow up USQ and BSQ were identical, except that "in the past six months" was replaced by "in the past month".

\begin{tabular}{|c|c|c|c|c|c|c|}
\hline & \multicolumn{6}{|c|}{ a Please complete the following questions by circling the response that most closely describes your child's urinary behavior. } \\
\hline & $\begin{array}{l}\text { Use the scale of } 0 \text { to } 4 \text { where: } \\
4 \text { is 'almost always' } \\
3 \text { is 'more than half the time' } \\
2 \text { is 'about half the time' } \\
1 \text { is 'less than half the time' } \\
0 \text { is 'not at all' } \\
\text { In the past six months }\end{array}$ & Almost always & $\begin{array}{l}\text { More than } \\
1 / 2 \text { the time }\end{array}$ & $\begin{array}{l}\text { About } 1 / 2 \text { the } \\
\text { time }\end{array}$ & $\begin{array}{l}\text { Less than } \\
1 / 2 \text { the time }\end{array}$ & Not at all \\
\hline 1 & $\begin{array}{l}\text { If we are away from home, for example shopping at } \\
\text { the mall, my child has to } \\
\text { pass urine frequently, so that we know where } \\
\text { bathrooms are in most stores. }\end{array}$ & 4 & 3 & 2 & 1 & 0 \\
\hline 2 & $\begin{array}{l}\text { My child has to rush to the bathroom when he/she } \\
\text { needs to pass urine. }\end{array}$ & 4 & 3 & 2 & 1 & 0 \\
\hline 3 & $\begin{array}{l}\text { When my child needs to pass urine he/she holds } \\
\text { himself/herself, squats down, } \\
\text { crosses his/her legs or dances around. }\end{array}$ & 4 & 3 & 2 & 1 & 0 \\
\hline 4 & $\begin{array}{l}\text { My child gets up at night to pass urine or has had } \\
\text { "wetting accidents". }\end{array}$ & 4 & 3 & 2 & 1 & 0 \\
\hline & Total Score & & & & & \\
\hline
\end{tabular}

\begin{tabular}{|c|c|c|c|c|c|c|}
\hline & \multicolumn{6}{|c|}{$\begin{array}{l}\text { b Please complete the following questions by circling the response that most closely describes your child's bowel elimination } \\
\text { behavior. }\end{array}$} \\
\hline & $\begin{array}{l}\text { Use the Scale of 0-4 where: } \\
4 \text { is 'almost always' } \\
3 \text { is 'more than half the time } \\
2 \text { is 'about half the time } \\
1 \text { is 'less than half the time' } \\
0 \text { is 'not at all' } \\
\text { In the past six months: }\end{array}$ & Almost Always & $\begin{array}{l}\text { More than } \\
\text { half the time }\end{array}$ & $\begin{array}{l}\text { About half } \\
\text { the time }\end{array}$ & $\begin{array}{l}\text { Less than } \\
\text { half the time }\end{array}$ & Not at all \\
\hline 1 & $\begin{array}{l}\text { My child has gone longer than } 2 \text { days between } \\
\text { having a bowel } \\
\text { movement }\end{array}$ & 4 & 3 & 2 & 1 & 0 \\
\hline 2 & $\begin{array}{l}\text { My child has had blood on the tissue after he/she } \\
\text { has a bowel } \\
\text { movement }\end{array}$ & 4 & 3 & 2 & 1 & 0 \\
\hline 3 & $\begin{array}{l}\text { My child has had excessively large bowel } \\
\text { movements }\end{array}$ & 4 & 3 & 2 & 1 & 0 \\
\hline 4 & My child has had small hard bowel movements & 4 & 3 & 2 & 1 & 0 \\
\hline 5 & $\begin{array}{l}\text { My child has "accidents" from bowel movements } \\
\text { including } \\
\text { stains (skid marks) in the underwear }\end{array}$ & 4 & 3 & 2 & 1 & 0 \\
\hline & Total score & & & & & \\
\hline
\end{tabular}


TABLE 2

Patient Demographics and Questionnaire Scores

\begin{tabular}{|c|c|c|c|c|}
\hline & $\begin{array}{c}\text { Placebo, } \\
\mathbf{n}=\mathbf{3 8}\end{array}$ & $\begin{array}{l}\text { Polyethylene } \\
\text { Glycol, n=33 }\end{array}$ & $\begin{array}{l}\text { Non- } \\
\text { Completers, } \\
n=67\end{array}$ & P-Value \\
\hline Female $(\%)$ & $24(64.9 \%)$ & $20(64.5 \%)$ & $41(61.2 \%)$ & $\mathrm{P}=0.970^{+}$ \\
\hline Age (SD), years & $7.1(2.5)$ & $7.5(2.5)$ & $7.4(2.2)$ & $\mathrm{P}=0.670^{\wedge}$ \\
\hline Weight (SD), kg & $32.8(16.5)$ & $32.9(19.5)$ & $30.7(13.5)$ & $\mathrm{P}=0.829^{\prime}$ \\
\hline Initial USQ (SD) & $13.9(2.5)$ & $13.9(2.6)$ & $13.9(2.7)$ & $\mathrm{P}=0.957^{\wedge}$ \\
\hline Follow-Up USQ (SD) & $10.5(4.6)$ & $10.2(4.6)$ & N/A & $\mathrm{P}=0.832$ \\
\hline USQ Change (SD) & $3.4(4.3)$ & $3.7(4.4)$ & N/A & $\mathrm{P}=0.718$ \\
\hline USQ Improvement $\geq 3$ points, $\mathrm{n}(\%)$ & $17(44.7 \%)$ & $16(48.5 \%)$ & N/A & $\mathrm{P}=0.920^{+}$ \\
\hline USQ “complete response”, n (\%) & $5(13.2 \%)$ & $6(18.1 \%)$ & N/A & $\mathrm{P}=0.807^{+}$ \\
\hline Initial BSQ (SD) & $6.9(5.0)$ & $5.9(3.5)$ & $6.3(4.0)$ & $\mathrm{P}=0.745^{1}$ \\
\hline Follow-Up BSQ (SD) & $4.3(3.1)$ & $3.6(2.5)$ & N/A & $\mathrm{P}=0.303$ \\
\hline BSQ Change (SD) & $2.4(4.5)$ & $2.3(3.0)$ & N/A & $\mathrm{P}=0.914$ \\
\hline
\end{tabular}

$\hat{\text { Legend for statistical analysis: Kruskal-Wallis }}$

Mann-Whitney U

${ }^{+}$Chi-square 


\section{TABLE 3}

Fecal Load on KUB. KUB grading was performed by a pediatric radiologist blinded to treatment group. The validated Leech and Blethyn grading scales were used. ${ }^{1,2}$

\begin{tabular}{|l|l|l|l|}
\hline & Placebo, n=38 & PEG, n=33 & $\begin{array}{l}\text { Non-completers with } \\
\text { baseline KUB, n=58 }\end{array}$ \\
\hline \begin{tabular}{l|l|l} 
Mean (SD) Leech Score \\
Baseline
\end{tabular} & $\begin{array}{l}\text { (2.08 (2.96) } \\
\text { After 1 month }\end{array}$ & $\begin{array}{l}7.58(2.03) \\
7.79(2.73)\end{array}$ & $\begin{array}{l}7.90(2.61) \\
\text { N/A }\end{array}$ \\
\hline $\begin{array}{l}\text { \# (\%) Constipated by Leech criteria } \\
\text { Baseline }\end{array}$ & $22(57.9 \%)$ & $18(54.5 \%)$ & $21(36.8 \%)$ \\
After 1 month & $21(55.3 \%)$ & $19(57.6 \%)$ & N/A \\
\hline $\begin{array}{l}\text { Mean (SD) Blethyn Score } \\
\text { Baseline }\end{array}$ & $1.79(0.70)$ & $1.47(0.57)$ & $1.67(0.57)$ \\
After 1 month & $1.71(0.57)$ & $1.71(0.59)$ & N/A \\
\hline $\begin{array}{l}\text { \# (\%) Constipated by Blethyn criteria } \\
\text { Baseline }\end{array}$ & $26(68.4 \%)$ & $14(42.4 \%)$ & $39(68.4 \%)$ \\
After 1 month & $25(65.8 \%)$ & $23(69.7 \%)$ & N/A \\
\hline
\end{tabular}

